\title{
A Glimpse of the Inevitable
}

Inundated with thick, puffy legs and coarse beards tinged with yellow, engulfing smiles exuding carefree air.

She was immediately different.

Her eyes wide with something unattainable by empathy, surrounded by people pretending to have it all together, just for her.

The room brimming with false pretenses,

balloons and smiles flirting with my vision until I take my first breath,

filling my heart with the weight of the air.

Words emerge, but my mind wanders,

a defense mechanism of sorts.

I stumble upon her mirror image: a bedside stuffed owl,

preposterous given the backdrop,

its eyes wide and expression gaping,

casting wisdom that has lost its meaning aside.

She did everything right, but it didn't matter.

Her body losing its desire to serve,

her heart could not carry her mind any longer,

trapping her in skin and bones that shivered in the heat of her realization.

She did everything right, but it didn't matter.

She still ended up in this place,

her entire being succumbing to our so-called medicine,

tricking the mind into tranquility,

forgiving her heart for giving out.

For decades now reduced to seconds,

she embraced what we said,

what we promised would help.

Years gained but acceptance waned,

the mind demanding more and more,

the body offering less and less.

She did everything right, but it didn't matter.

Disappearing in the night,

grown men crashing into waves of salty water,

white squares playing rafts.

My eyes staring back at me from the bedside mirror.

Kelsie Riemenschneider

Correspondence to Kelsie Riemenschneider, Vanderbilt University School of Medicine, 2215 Garland Avenue, Nashville, TN 37232, USA; kelsie.riemenschneider@vanderbilt.edu

Competing interests None.

Provenance and peer review Not commissioned; internally peer reviewed.

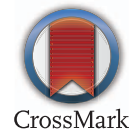

To cite Riemenschneider K. Med Humanit 2017;43:e1.

Published Online First 26 August 2016

Med Humanit 2017:43:e1. doi:10.1136/medhum-2016-011034 